\title{
Vaccines developed in United States to be tested in India
}

\section{New Delhi}

INDIA will become the testing ground for several new vaccines being developed in the United States, following an Indo-US agreement last week on a Vaccine Action Programme (VAP) "to develop and test vaccines and diagnostic techniques for major communicable diseases"

The agreement, signed by $\mathrm{Mr}$ John Gunther Dean, the American Ambassador, and Dr S. Ramachandran, Secretary of the Department of Biotechnology, has paved the way for trying out in India advanced and genetically engineered vaccines that might, for practical reasons, be difficult to test in the United States.

India has always been sensitive on the issue of its people being used as guineapigs for the trial of drugs and vaccines developed elsewhere, which is one reason for the delay of nearly 18 months in signing the agreement. This difficulty has now been met by the United States, which has associated Indian scientists with the US laboratories where the vaccines are being developed.

What form this association will take is not clear; most of the US vaccines are already in an advanced stage of development and waiting only for clinical evaluation. But by projecting the vaccines as products of Indo-US collaboration, the United States hopes to avoid opposition to clinical trials in India.

Among the vaccines to be tested are those against diarrhoeal diseases (rotavirus, cholera, shigella, $E$. coli and salmonella), a cellular pertussis vaccine, an oral typhoid vaccine and a recombinant

departments at Cambridge, Edinburgh, Manchester and Sussex, expansion (if anything) at Bath and Lancaster, restructuring at Manchester, Oxford and London ("where two or three potentially major centres have been allowed to run down to the point at which they are barely viable") and the continuation of most other activities in the field.

\section{Ocean resources \\ London}

Resources from the oceans could provide a world market worth more than $\$ 160,000$ million a year, according to series of studies commissioned by the UK Department of Trade and Industry. The documents are mostly concerned with deep-sea mineral reserves, offshore petroleum and seabed mapping. While British continental shelf resources are not estimated to be large, the reports (which have cost $\mathfrak{\$ 3 0 0 , 0 0 0}$ ) say that there may be a demand for British skills.

K.J.
DNA vaccine against hepatitis-B. The collaboration also provides for the testing of the vaccinia/rabies glycoprotein recombinant vaccine developed at the Wistar Institute and used in a controversial experiment on cattle in Argentina (see Nature 324, 610; 1986).

The inclusion of the Wistar vaccine in Indian trials has raised eyebrows among a section of the medical community, but Ramachandran says the Argentine experience will not be repeated in India. $\mathrm{He}$ says that the Argentine controversy arose because Wistar failed to inform the government. He said that there are 7 million dog bites a year in India; it is proposed to control rabies in stray dogs by mixing the recombinant vaccine with dog food. In Argentina, the vaccine was inoculated.

The five-year project is estimated to cost $\$ 9.6$ million, out of which the US government will contribute $\$ 7.6$ million. Besides the Department of Biotech- nology, the Ministry of Health and the Indian Council of Medical Research (ICMR) will implement the project.

Allaying fears that the agreement with the United States will make Indians guinea-pigs, Ramachandran said the rights and welfare of human subjects of research will be protected, taking into account the laws and regulations in both countries. Clearance would be obtained from the drug controller of India before tests of the vaccines, he said.

Whether or not the United States will succeed in testing its vaccines depends on the ICMR, which advises the drug controller whether a vaccine should be tried on humans. Dr A.S. Paintal, director general of ICMR and a stickler for medical ethics, said he would not allow any vaccine to be used in India unless it was also approved for use in the United States by the Food and Drug Administration.

As for the US motive in collaborating with India, Paintal says it represents only the natural curiosity of scientists to find out the efficacy of their vaccines by testing them in places where the diseases exist.

K.S.Jayaraman

\section{British compromise with Europe over research programme}

\section{London}

SCIENTISTS involved in projects supported by the European Community's research programme are relieved that the longrunning feud between Britain and its partners has been virtually resolved. But, after months of blocking by Britain, the compromise programme has a far slimmer budget than originally proposed.

Community ambassadors have agreed on a five-year programme costing 5,200 million ECU (European Currency Units, $1 \mathrm{ECU}=£ 0.69$ ), 417 million ECU less than the amount supported by all other 11 member states in March. Britain is still formally blocking the extra 417 million ECU, but will agree before the end of the year on condition that progress is made on curbing other expenditure, especially on agriculture. An additional 800 million ECU will be available for commitment during the next five years, but cannot be spent until after 1991

The compromise came after Britain changed its definition of "existing expenditure" on the programme. The Prime Minister, Mrs Margaret Thatcher, had told last months summit that Britain would agree to maintain the research at the level of existing expenditure so that important projects could continue; originally, the British government had argued that existing work was equivalent to 4,000 million ECU only.

The programme will be drawn up as though the full 5,600 million ECU is available, which observers see as an indication of Britain's willingness to compromise.

Ministers are expected to give formal approval to the programme this week. The European Parliament will discuss it in September, and no funds will be officially released until after that. The parliament had threatened to withhold funds in the areas of telecommunications, medical research and science and technology for the developing world unless the overall five-year framework was agreed.

The compromise should mean cooperative research programmes such as Esprit (information technology) and Race (broadband telecommunications), as well as others, can continue without further interruption. But some research has already suffered because of the long delay - the European Commission says the second phase of Esprit could be set back, with some researchers temporarily laid off, and the European Parliament Research Committee has been told that British Telecom has had to disband its telecommunications research team.

Some scientists, puzzled by Britain's long battle against the research programme, point out that for every $£ 1$ Britain puts into joint community research, up to $£ 1.30$ comes back in contracts.

"After all this delay, everybody in Europe has lost", says European member of parliament Glyn Ford, a member of the research committee.

Kathy Johnston 